\title{
Errors in the Use of Prepositions by Maithili Learners of English and Their Remedies*
}

The present paper attempts to describe the errors in the use of prepositions by Maithili learners of English, account for them in the ing strategies, and suggest their remedies.

\author{
I lately lost a preposition; \\ It hid, I thought, beneath my chair \\ And angrily I cried: "perdition!" \\ Up from out of in under there!" \\ Morris Bishop: "The Naughty preposition!" \\ A Bowl of Bishop.
}

\section{INTRODUCTION}

1. Need: The standard of English in Nepal has very much worsened. Even after years of study at schools. and campuses, the learners of Engnot able to consage, do not possess the required proficiency. They are in their English. What English' - a term used byey speak or write may be called 'Fractured of English which is often Rivers and Temporley (1978) to suggest 'a kind to Improve their Es the learners' errors. insight into the learners' kind of study will help the teachers gain right kind of teaching errors and can be a feed-back for choosing writers in incorporating In Nepal, Malthili occupies second teaching items in the remedial courses. of speakers, and learners Hence, this kind of study will deal of this community form a large group. learners of English.

2. Data and Their Analysis: For this purpose, the paper-writer administered a test to the Maithill learners of English at his Campus. The most frequently the linguistic area in which the learners made errors most frequently was in the use of prepositions. The paper-writer has, of prepositions.

*This paper is based on the Project Work for the partial fulfilment of the course in PGDTE, CIEFL, Hyderabad, 1980.

'A.K: Tha is associated with S.M.B.M Campus, Rajbiraj, Nepal. 
3 Objective and Procedure of the Analysis: The paper attempts to examine the causes of errors and to provide solutions to eliminate such errors. The procedure of the analysis is as follows:

1. Prepositions in English and Matthili: a brief contrastive study.

2. Types of errors.

3. Causes of errors.

4. Pedagogical implications.

5. Conclusions.

1. PREPOSITIONS IN ENGLISH AND MAITHILI: A BRIEF CONTRASTIVE STUDY

1.1 The use of prepositions is the most cruclal problem for the Maithili learners of English. These short, simple, innocent-looking prepositions of English are, infact, very tricky. Takahashi (1969) writes: "Aside from the correct usage of particles, the greatest problem facing the students of English as a second language is, no doubt, the correct usage of English prepositions." These prepositions sometimes, become a problem even for the native speakers. An obvious reason is that the number of prepositions used in English are limited but they have to serve a variety of relational meanings. These prepositions form a closed system. In Maithili, too, the prepositions or, what is technically called, postpositions form a closed system. There are, however, some fundamental differences between the prepositions in English and the postpositions, in Maithili. The postpositions in Maithili are even fewer than the prepositions in English. As a result, when Malthili uses one postposition for expressing one kind of relational meaning, English uses a number of prepositions for expressing the same kind of relational meaning depending upon its meaning dimension. For instance, a single Maithili postposition of time 'Me' imparts the same relational meaning which four English prepositions 'at, in, on, during, do, but, in the latter case, they exhibit different shades of relational meaning of time. In this way, there are about eight postpositions of time in Maithili while English uses seventeen prepositions for the same. This makes the task of Maithili learners of English more complex. Another point of difference is that postpositions in Maithili do not behave like adverbial particles as we find in English. Thus, the behaviour of prepositions may prove very confusing for Maithili learners. Here, owing to the problem of space, only the prepositions of time, of position and direction in English and their equivalents in Maithili are given below together in charts:

(1) Prepositions of Time

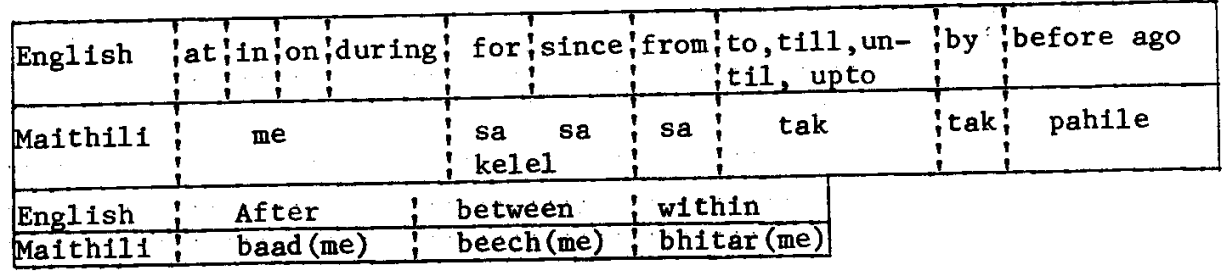


(2) Prepositions of Position and Direction

\begin{tabular}{|c|c|c|c|c|c|c|c|}
\hline Ėnglish & in at & ion & off out of & away from & (on) to & Between & among \\
\hline Maithili & me me par & par: & (sa) & baahar & par & beech (me) & \\
\hline
\end{tabular}

\begin{tabular}{|c|c|c|c|}
\hline English & under below down beneath & over above up (up) on & by near about \\
\hline Maithili & neecha, tar & (u) par & $\operatorname{lag}$ \\
\hline
\end{tabular}

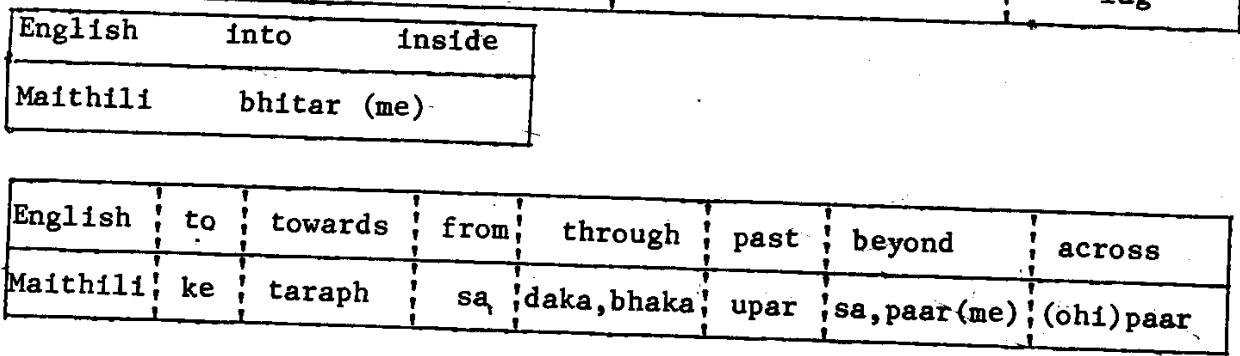

\section{TYPES OF ERRORS}

2.1 In order to study the learners' errors, it is necessary, first of in extracting the erroneous sentences it is essential to point out that, errors which are 'systematic' and 'asystention has been given to those errors. 'Systematic' errors and 'asystematic', not to 'unsystematic' which are caused by the learners! 'Asystematic' errors, according application of overgeneralisation. eralizations which have not acquired the are those which 'stem from' gento stay as hypothesis. Again, 'status of rules but continue are those which are silps of the tongue ogical reasons. Such 'unsysteme tongue or pen, caused by purely psycholthis study because they do not ly speaking, there are three typese the pedagogical significance. Broadpreposition which can be det types of errors in relation to the use of of English.

\subsection{Omission of Preposition: The learners drop using any preposition in the sentence where it is obligatory as in (3)}

(3) a) I woke up in the morning $50^{\prime}$ clock.

b) My class started 10 to $40^{\prime}$ clock.

c) I was waiting the bus.

d) I explained my teacher why I was late.

e) I came my lodge. 
2.1.2 Insertion of Preposition: Students supply prepositions in the sentences where it is undesirable as in (4).

(4) a) I reached to the Campus.

b) I saw to my teacher.

c) I read the books since to $40^{\prime}$ clock.

d) He has described about the incident.

e) My teacher entered into the class.

2.1.3 Selection of Incorrect Preposition: Students supply prepositions in their sentences which are not appropriate. This type of error as in (5) is in greater frequency.

(5) a) I came here in the 15th of July.

b) I came in Campus at $100^{\prime}$ clock.

c) My father prevented me to go to the film.

d) He has done it from a systematic manner.

2.2 All these types of errors are local, not global. "Global errors", according to Marina, Bust and Kiparsky (1972) are mistakes in overall organisation which confuse the relations among the constituent clauses: "local errors", according to them, are errors within clauses. The erroneous use of preposition in the above cited examples is local because it does not "Interfere with comprehension."

\section{SOURCES OF ERRORS}

3.1 It is not easy to specify the sources of errors. Sometimes, errors are so complex and ambiguous that it is difficult to regard one particular source as responsible for that error. However, it is essential to explore the source of our learner's errors for arriving at certain measures to eradicate them. The erroneous sentences cited in the previous section indicate that they are mainly two sources of learner's errors-interlanguage interference and intralanguage interference.

3.1.1 Intralanguage Interference: When the learner, after mastering his mother tongue, is exposed to a target language, it is a natural process that he applies transfering some of the rules of his $L 1$ to his target language. Sometimes, this transfer is positive when the rule of his mother tongue fits into the system of his target language. But, sometimes, this transfer is negative when it does not conform to the system of the target language. This negative transfer is called 'interlanguage interference.' The pull of mother tongue is responsible in three ways for the learners' errors in the use of prepositions.

3.1.2 In Maithili, no postposition is required in sentences where it is obligatory in Engilsh as in (6). Sometimes, in Maithili, there is the choice of omftting or inserting a certain postpositions, while, in English, it is obligatory as in (7). 
(6) Maithil1 : ham gaam elahu.

(I village came)

English : I: came to the village.

(7) Maithili : ham ahhake chair baje bhetab.

(I you 4 o'clock shall meet)

English : I shall meet you at 4 o'clock.

The Maithill learners of English are Influenced by the system of their own language and, as a result, they write erroneous sentences like:

(8) I went market $50^{\prime}$ clock.

I studied there three hours.

I took my breakfast $7 \mathrm{a} . \mathrm{m}$.

This kind of error may be attributed to 'communicative strategy' but the pull of mother tongue cannot be underestimated as a source for this kind
of error.

3.1.3 In Maithili, if a noun (not a pronoun) is the indirect object of a transitive verb, it must take a postposition 'ke'. In English, the intain order of words. e.g.:

(9) Malthil1: ham ee kitab Sita ke Deliyanhi.

(I this book Sita to gave)

English : 1) I gave this book to sita.

11) I gave Sita this book.

In the above Maithill sentence, the postposition 'ke' is obligatory; it is so in English sentence 1) but the preposition ' $t$ ' has to be dropped in English sentence 11). SImflarly, in the case of verbs which take only one object, no preposition is used before the object in English. On the other hand, nouns in Maithili will take postposition if they are the objects of such verbs. e:g.

(10) Maithill : ham Ram ke dekhallyanhi.
(I Ram to saw)
Engl1sh : I saw Ram.

Such difference between the source language and the target language becomes a barrier for our learners. The system of mother tongue makes its own demand and, as a result, the learner writes sentences like:

(11) I saw to my teacher.

I read to the books since 4: $0^{\prime}$ clock. 
3.1.4 Another reason which is largely responsible for the learners' errors is that there is no one-to-one correspondence between Maithill postposition and English preposition. It has been pointed out earlier that Maithili postpositions are fewer in number than Egnlish prepositions and Malthili: postpositions have general meaning, whereas English prepositions have specific meaning. The learners, in the early stage of learning, realise the meanings of English prepositions by substitute postpositions of Maithili. In this process, he, sometimes, translates mentally three or four English prepositions into one Maithili postposition so that the distinction among these English prepositions gets lost. As a result of this tendency to supply exact equivalent of Maithili postpositions in English, they write erroneous sentences like these:

(12) I came in Campus at 4 o'clock.

I have not studied since two hours.

The girl is afraid from the snake.

He was laughing on me.

3.2 Intralanguage Interference: In the process of learning the target language, the adult learner adopts a strategy to simplify the system of the target language by coalescing two or three rules into one and forming an overgeneralisation. This is a natural process which even a child adopts for acquring his Ll. But the difference is that while a child expands his simplified system to give a one-to-one correspondence with the adult language of his community, the second language learner is contented with working upon the simplified system, without further assimilating the subsystem of his target language. This is the case of overgeneralization which crops up in the process of his learning the target language. In the use of preposition, our learner makes overgeneralization of two kinds.

3.2.1 Sometimes, the learner overgeneralizes because of some meaning association between certain words. The learner finds that these pairs of words like 'reach' and 'go', 'enter' and 'come', 'describe' and 'say', 'tell' and 'explain' are alike' in meaning and forms a wrong analogy about their usage. While the first item of every pair will not generally take a preposition, the second term of every pair will take a particular preposition. If a learner has made a generalization on the basis of first item, he will drop preposition even in the case of second item and vice versa. The result is the use of their erroneous sentences like these:

(13) I reached to the Campus. He described about the incident. You will tell to me later. I explained to my teacher why I was late.

3.2.2 Certain words in English take certain fixed prepositions. In the same way, certain words which usually take prepositions drop them in certain environment. The learner forgets this kind of lexical restriction and is led to go of. The students make errors of overgeneralization like the following:

(14) I came to home. My father prevented me to go to the film. 
I introduced him with my father.

I am tired with him.

The learner finds correct use of prepositions in the sentence 'I came to my village' and this lead him logically to arrive at an incorrect sentence like "I came to home." Certain verbs, underlined in the above stentences take certain prepositions. The use of prepositions in such cases has to be learnt individually. The learner in the process of simplifying the system of his target language makes a generalization which is not valid in such cases.

3.2.3 Sometimes, the learners make errors as a result of such generalizations about the use of preposition which have not acquired the status of rules. These generalizations, Mr. M.P. Jain (1973) says, continue to stay as hypotheses; they are open to unsettling influences. As a result, the learner is unable to apply these generalizations with any degree of consistency. This is not the case of systematic type of error. Mr. M.P. Jain calls such an error as an asystematic error. Here is an example from the learner's writing:

(15) Yesterday, I got up early in the morning. I took my breakfast at $70^{\prime c l o c k . ~ I ~ g o t ~ r e a d y ~ f o r ~ s t u d y ~ i n ~ t h e ~ h a l f ~ p a s t ~ s e v e n . . . ~}$ My class started 10 'clock.

Here, the language is not 'rule-governed' behaviour. The learner has not formed any definite : ule about the use of 'at' and 'in' as prepositions of time. He uses hit or miss strategy.

3.3 Besides these two sources of the learners' errors mentioned above, there are other factors responsible for their error in the use of prepositions. They are -- the type of course book, the type of grammar book, teaching technique and the motivation of the learners. At schools, English syllabus in totality provides a very little opportunity for the learners to learn the use of prepositions. In the entire English courses at schools, there are merely three or four isolated exercises on prepositions without any suitable contextualised illustrations. The secondary graduates come to the University without any firm knowledge about the use of prepositions. In this case, the present compulsory English syllabus of Tribhuvan University is no better since it does not have any genuine remedial course to hel $\dot{p}$ the learners eliminate their errors in the use of prepositions. 'English for Colleges', prescribed for PCL I of all faculties, has a separate unit on the teaching of grammar and this portion may be considered as remedial in nature but it makes no mention of the use of prepositions. In the same way, most grammar books lack quality in teaching and variety in exercises and most teachers lack in techniques in grammatical presentation for helping the learners form valid generalisations about the use of prepositions. Most grammar books and teachers state the same thing that 'for' as a preposition of time is used for a period of time and 'since' for a point of time. The lack of contextualisation frustrates the learners to undo the bad learning and to build up new, correct inguistic habits. The errors persist till they get fossilised in the brain of the learners. Finally, the learners 
tend to lose all motivation and find themselves unable to refine and expand their mini-grammar. Thus, regarding the learners' error in the use of prepositions, all these factors discussed in th1s section contribute to the process of "fossilization" (L. Selinker, 1972) on the part of learners.

\section{PEDAGOGICAL IMPLICATIONS}

4.1 In order to overcome the mother tongue interference, it is desirable to warn the learners against their tendency to equate English prepositions with Maithili postpositions. We should show the learners by some precise examples how the postpositions in their Ll overlap with English prepositions. If there is a simflarity between the use of preposition of both $\mathrm{Ll}$ and L2, this must be demonstrated before the learners for facilitating their learning.

4.2 With regard to interlanguage interference, it is necessary to improve the learners' capacity to generalise. The generalizations must include all the sub-rules about the use of preposition.

4.3 For encouraging the learners to establish the broader generalizations, there must be the learners' adequate exposure to the target language.

4.4 The main emphasis must be given on the teaching strategy and the materials by which the learners will form generalisations about the use of prepositions and will "internalise" them. All the prepositions should not be taught at a time. They should be classified on the basis of meaning they convey like prepositions of time, place, direction, purpose, etc. Before starting teaching any type of prepositions, the teachers should make a good planning. The materials must be well-suited; they must be interesting and must provide ample illustrations of prepositions. After the presentation of the material, the learners should be asked questions involving the use of prepositions of the same type. Then, the learners should be helped to form valid generalisations on the basis of illustrations from the text and from the learners' response. Finally, the learnners should be administered a test with exercises in variety for reinforcement. This method af teaching grammar is a combination of both induction and deduction; Corder, S. Pit (1973) calls this method "a guided inductive method."

4.5 After teaching all the prepositions based on notions, like prepositions of time, of place, of direction, of purpose, etc., the prepositional phrases like 'on account of', 'by means of' and the collocations of prepositions with certain verbs, nouns and adjectives should be taught. Such phrases and collocations are 'open-ended' and, $11 \mathrm{ke}$ other lexical items, they have to be selected, graded and sequenced on the principle of frequency and range of their occurrence.

\section{CONCLUSION}

5.1 The error in the use of preposttions by Malthill learners of English is really a matter of great concern for the teachers. Our University 
entrants have formed bad language habits. In the absence of sufficient exposure to English at schools, the bad language habits espectally with regards to the use of prepositions persisted and, at the Campus level, the task of their getting into correct language behaviour naturally becomes all the more complex. However, the problem can be overcome if the teacher makes a concerted attempt at rectifying their error. In this paper, an attempt has been made to analyse the learner's error in relation to the use of prepositions and some measures have been suggested. If the measures are adopted adequately, they will help the teacher to eliminate his learner's errors.

\section{References Cited}

Bishop, Morris, "The Naughty Preposition", A Bowl of Bishop.

Burt, Marina and Kiparsky, The Gooficon: A Repair Manual for English, Massachusetts, Newbury House, 1972 .

Corder, S. Pit, Introducing Applied Linguistics, England, Penguin Books, 1973.

Jain, M.P., Error Analysis: Sources, Cause and Significance in Richards, J.C. (ed. 1974), Error Analysis: Perspective on Second Language Acquisition, London, Longman, 1973.

Rivers, W. and Temperley, M.S., A Practical Guide to the Teaching of English as a Second or Forelgn Language, London, (OUP, INC.), 1978.

Selinkar, L., Interlanguage in Richards, J.C. (ed. 1974).

Takahashi, George, Perception of Space and Function of Certain English Prepositions, Language Learning, 19 December, 1969. 